\title{
MODEL PERILAKU NET BUYING SELING (NBS) UNTUK SAHAM HMSP SELAMA PERIODE AKUISISI DARI PHILIP MORRIS
}

\author{
Ignatius Roni Setyawan \\ Jurusan S1 Manajemen, Universitas Tarumanagara Jakarta \\ Email:ign.s@fe.untar.ac.id
}

Masuk: 12-04-2019, revisi: 12-09-2019, diterima untuk diterbitkan : 27-09-2019

\begin{abstract}
ABSTRAK
Dalam akuisisi di perusahaan yang memiliki reputasi hebat di pasar riil dan pasar keuangan, maka analisis faktor dampak dari akuisisi tersebut bagi investor pasar modal adalah penting untuk dilakukan. Hal ini karena setelah akuisisi akan terjadi perubahan struktur bisnis dan pemilik yang akan mempengaruhi arah kebijakan peusahaan di pasar modal dan biasanya ini dinantikan oleh para investor. Seperrti kasus go private Aqua pasca diambil alih Danone dan Semen Padang dan Tonasa oleh Cemex, maka akuisisi Philip Morris ke Sampoerna akan begitu dinantikan. Dengan begitu studi ini akan fokus pada varaibel net buying selling yang menjadi ukuran langsung dalam proses akuisisi. Hal ini dikarenakan dalam akusisi akan terjadi proses pembelian (penyerahan) dan penjualan (pelepasan) saham dari pemilik ke pihak pengakusisinya. Studi ini masih bersifat awal dalam topik penelitian sejenis, karenanya akan memakai model peramalan ARIMA (teknik Box Jenkins). Berdasarkan analisis ekonometrika secara time series mulai dengan uji stasioneritas ternyata terbukti bahwa variabel net buying selling sudah stasioner tanpa differencing prosess. Kedua hasil uji stasioneritas yakni uji korelogram membuktikan dari lag 1 - 28 tanda * atau spike dari net buying selling masih dalam batas garis Barlett untuk grafik ACF dan PACF. Sedangkan berdasarkan uji unit root ADF (random walk with drift and trend) terbukti nilai ADF-statistik sebesar 6.032041 masih lebih kecil dari nilai ADF-kritis $(\alpha=5 \%)$. Kemudian waktu melakukan uji identifikasi model mulai AR(1), MA(1), ARMA (1,1) yang akhirnya didapat model terbaik yakni ARMA (1,1). Model ARMA (1,1) selanjutnya dipakai sebagai model prediksi bagi para investor.
\end{abstract}

Kata Kunci: Net Buying (Selling), HMSP, Philip Morris, Akuisisi, Investor Asing

\begin{abstract}
In an acquisition in a company that has a great reputation in the real market and financial market, it is important to analyze the impact factor of the acquisition on capital market investors. This is because after the acquisition there will be a change in the structure of the business and the owner which will influence the direction of the company's policy in the capital market and this is usually expected by investors. As with the case of going private Aqua after being taken over by Danone and Semen Padang and Tonasa by Cemex, the acquisition of Philip Morris to Sampoerna will be expected. That way this study will focus on net buying selling variables which are a direct measure of the acquisition process. This is because in the acquisition there will be a process of buying (handing in) and selling (releasing) shares from the owner to the acquirer. This study is still preliminary in the topic of similar research, therefore it will use the ARIMA forecasting model (Box Jenkins technique). Based on the time series analysis of econometrics starting with the stationarity test it turns out that the net buying selling variable is stationary without differencing processes. The two stationary test results, the corelogram test, prove that lag $1-28$ sign * or spike of net buying selling is still within the limits of the Barlett line for ACF and PACF charts. While based on the ADF root unit test (random walk with drift and trend) the ADF-statistic value proved to be -6.032041 still smaller than the ADF-critical value $(\alpha=5 \%)$. Then when testing the model identification starting from AR (1), MA (1) and ARMA (1,1) which finally the best model is obtained, namely ARMA $(1,1)$. The ARMA model (1.1) is then used as a prediction model for investors.
\end{abstract}

Keywords: Net Buying (Selling), HMSP, Philip Morris, Acquisitions, Foreign Investors

\section{PENDAHULUAN}

\section{Latar Belakang}

Sebagai salah satu perusahaan rokok kretek terbesar dan memiliki pengaruh kuat di pasar modal Indonesia, maka PT H.M. Sampoerna selalu menjadi daya tarik bagi investor asing. Sudah sejak lama banyak kelompok investor asing besar yang mencoba menguasai kepemilikan saham PT 
H.M. Sampoerna mengingat potensi pasar dan ekonomi dari rokok kretek Sampoerna. Salah satu investor asing yang kuat yang sangat berambisi mengambil kepemilikan saham Sampoerna adalah Philip Morris. Yang menjadi motif dari Philip Morris ini adalah kekuatan rokok kretek dan akses pada bahan baku rokok seperti tembakau dan cengkeh serta tenaga kerja yang terampil dalam produk sigaret kretek tangan. Dengan mengambil alih saham PT HM Sampoerna (HMSP) maka Philip Morris (PM) akan memperoleh sinergi rokok kretek dan putih demi daya saing internasional.

Setelah sekian lama terhalang oleh konservatisme dari keluarga Sampoerna maka akhirnya pada tanggal 12 Maret 2005 ambisi akuisisi dari Philip Morris ini terwujud. Tulisan ini akan mencoba tidak membahas pada proses akuisisinya melainkan pada dampaknya di pasar modal. Karena akuisisi begitu akan ditunggu realisasinya oleh investor. Penulis hanya akan fokus pada variabel net buying selling oleh karena varibel ini akan menunjukkan apakah ada investor asing selain Philip Morris yang ikut memainkan peranan dalam akuisisi dengan mengambil peran di pasar modalnya. Dengan demikian tujuan dari studi penulis ini adalah untuk mengidentifikasi model perilaku pergerakan variabel net buying selling dari foreign investor untuk akuisisi saham HMSP per tanggal 12 Maret 2005. Sebagaimana dikutip dari Investor Daily, 15 Maret 2005 akusisi Phillips Morris (PM) sebesar 40\% dari saham HMSP (lihat keluarga Sampoerna) cukup menimbulkan pro dan kontra di kalangan pasar modal. MISI (Masyarakat Investor Seluruh Indonesia) cukup mendukung karena menilai akuisisi ini sebagai taktik Phillips Morris untuk mengembangkan bisnis rokok putih di Indonesia dan tidak melanggar aturan Bapepam IX H.1 tentang akuisisi perusahaan terbuka. Tetapi pengamat hukum pasar modal, Indra Savitri cukup skeptis dengan akuisisi tersebut karena prosesnya dilakukan pada saat hari bursa efek tidak beroperasi yakni Sabtu, 12 Maret 2005. Pro dan kontra juga dirasakan di kalangan intern HMSP sebab mereka takut terkena Pemutusan Hubungan Kerja (PHK). Karena secara teori keuangan, akuisisi oleh investor asing yang besar akan membawa dampak PHK karyawan lama. Melihat juga pada pengalaman akuisisi Cemex di Semen Padang dan Tonasa tahun 1998.

Lalu alasan diambilnya variabel Net Buying Selling dari investor asing adalah karena dalam beberapa riset seperti Frensidy (2006) dan Surjawan (2007) terindikasi bahwa Net Buying Selling dari investor asing terbukti begitu dominan dalam menggerakkan IHSG selama kurun waktu 2002-2006 dan sampai sekarang juga. Kalau Net Buying Selling ini terbukti signifikan secara agregat terhadap IHSG, maka variabel ini dapat diterapkan juga pada level individu saham. Berdasarkan penelusuran di www.idx.co.id, pada bagian FI.txt penulis berhasil menemukan data-data untuk foreign sell danforeign buy. Karena variabel yang dibutuhkan adalah net buying selling maka penulis melakukan penselisihan antara foreign sell dan foreign buy. Jika net buying selling memberikan tanda positif maka berarti lebih banyak investor asing yang membeli saham dan berpotensi akan menaikkan harga saham. Sebaliknya jika net buying selling memberi tanda negatif maka berarti lebih banyak investor asing yang menjual saham dan akibatnya harga saham turun. Penelitian ini berharap memberikan kontribusi ilmiah penelitian di bidang keuangan internasional yakni mengenalkan variabel net buying selling khusus saham bukan hanya net buying selling agregat yang selama ini sudah dikenal. Sehingga karenanya variabel ini dapat menjadi variabel eksplanatori untuk menentukan efektivitas diversifikasi internasional para investor asing tersebut. Maka penelitian ini bermaksud mengkonfirmasi hasil studi determinan aliran modal asing Saidah (2006), Tambunan \& Fauzie (2014), Dityadarma (2014) di Indonesia Bryne \& Viess (2016) serta Vo (2018) untuk data luar negeri. Mereka ini hanya melakukan riset pada level aliran modal asing global saja, sedang penelitian ini berada di level data korporasi. 


\section{METODE PENELITIAN}

Jenis penelitan ini adalah kuantitatif eksploratorif. Hal ini disebabkan penelitian ini membutuhkan data kuantitif yakni net buying selling dari saham HMSP selama periode 25/1/2005 sampai 25/4/2005 secara harian. Data net buying selling khusus saham harus diambil dari selisih antara foreign buy dan foreign sell yakni pada FI.txt dari www.idx.co.id (untuk periode sekarang FI.txt sudah dipindahkan ke www.ksei.co.id dan harus meminta login khusus untuk kepentingan riset). Selain karena data net buying selling HMSP bersifat kuantitatif dan berskala rasio (sudah dalam satuan rupiah) maka penelitian ini akan mengeksesuksikan model peramalan net buying selling saham dengan metode ARIMA (Autoregressive Integrated Moving Average) yang baru pertama kali dipakai dalam penelitian sejenis. Prosedur peramalan (forescating) sudah baku menurut teknik Box Jenkins yang meliputi: uji stasioneritas data dengan memakai korelogram; uji akar unit dengan Augmented Dicky Fuller (ADF) dan uji identifikasi model mulai dari AR, MA dan ARMA. Penentuan model terbaik dari F-hitung, Adj$\mathrm{R}^{2}$; AIC, SIC dan melihat pada minimal ada satu bentuk AR atau MA yang signifikan pada level $5 \%$ pada hasil estimasi model AR, MA dan ARMA.

\section{HASIL DAN PEMBAHASAN}

\section{Analisis dan Pembahasan Profil Data Net Buying Selling (NBS)}

Tujuan dari analisis ini adalah untuk mengetahui sejauhmana pola stasioneritas dari data NBS ini sudah dapat tercapai atau belum. Berdasarkan literatur ekonometrik maka pola stasioneritas penting untuk menjamin akurasi prediksi model yang dibangun [Hermanto (2009)].

Tabel 1. Analisis Korelogram dari Data Net Buying Selling dan

Hasil uji akar unit dengan ADF

\begin{tabular}{|c|c|c|c|c|c|c|c|c|}
\hline \multicolumn{2}{|c|}{ Autocorrelation } & \multicolumn{2}{|c|}{ Partial Correlation } & \multirow{2}{*}{\multicolumn{2}{|c|}{\begin{tabular}{c|c} 
& AC \\
1 & -0.110
\end{tabular}}} & \multirow{2}{*}{$\begin{array}{c}\text { PAC } \\
-0.110\end{array}$} & \multirow{2}{*}{$\begin{array}{l}\text { Q-Stat } \\
0.7663 \\
\end{array}$} & \multirow{2}{*}{$\begin{array}{l}\text { Prob } \\
0.381 \\
\end{array}$} \\
\hline .*1. & &.$*$ & & & & & & \\
\hline .1. & . & .1 & . & 2 & 0.027 & 0.015 & 0.8124 & 0.666 \\
\hline .1. & . & .1 & . & 3 & -0.034 & -0.030 & 0.8867 & 0.829 \\
\hline .1. & &.$*$ & . & 4 & -0.055 & -0.063 & 1.0894 & 0.896 \\
\hline $.1^{*}$ & *. & $.1^{*}$ & *. & 5 & 0.195 & 0.186 & 3.6601 & 0.599 \\
\hline .1. & . & .1 & . & 6 & -0.048 & -0.008 & 3.8215 & 0.701 \\
\hline .1. & . &.$*$ & & 7 & -0.053 & -0.074 & 4.0165 & 0.778 \\
\hline.$* 1$. & &.$* 1$ & . & 8 & -0.090 & -0.094 & 4.5902 & 0.800 \\
\hline .1. & . & .1 & . & 9 & 0.001 & 0.003 & 4.5902 & 0.868 \\
\hline.$* 1$ & &.$* 1$ & . & 10 & -0.090 & -0.136 & 5.1982 & 0.878 \\
\hline .1. & . & .1 & . & 11 & 0.045 & 0.023 & 5.3507 & 0.913 \\
\hline .1. & . & . & . & 12 & -0.017 & 0.014 & 5.3721 & 0.944 \\
\hline .1. & . & . & . & 13 & 0.027 & 0.052 & 5.4296 & 0.964 \\
\hline .1 . & . & . & . & 14 & -0.026 & -0.041 & 5.4852 & 0.978 \\
\hline .1. & . & .1 & . & 15 & -0.039 & -0.013 & 5.6131 & 0.986 \\
\hline .*1. & & $* * 1$ & . & 16 & -0.178 & -0.230 & 8.2840 & 0.940 \\
\hline .1. & . & * & . & 17 & -0.022 & -0.082 & 8.3240 & 0.959 \\
\hline $.1^{*}$ & *. & .1 & . & 18 & 0.075 & 0.043 & 8.8204 & 0.964 \\
\hline .1. & & .1 &. & 19 & -0.003 & 0.026 & 8.8214 & 0.976 \\
\hline .1. & & . & . & 20 & -0.047 & -0.076 & 9.0265 & 0.983 \\
\hline.$*$ & & & . & 21 & -0.099 & -0.025 & 9.9652 & 0.979 \\
\hline $.1^{*}$ & & & . & 22 & 0.075 & 0.064 & 10.510 & 0.981 \\
\hline .1. & & & . & 23 & 0.049 & 0.003 & 10.751 & 0.986 \\
\hline.$*$ & & 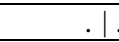 & . & 24 & 0.111 & 0.055 & 12.012 & 0.980 \\
\hline .1. & . & . & . & 25 & -0.056 & -0.028 & 12.342 & 0.984 \\
\hline .1. & . & .1 & . & 26 & -0.004 & -0.026 & 12.343 & 0.989 \\
\hline.$*$ & &.$*$ & & 27 & -0.110 & -0.155 & 13.697 & 0.984 \\
\hline .1. & . & * & . & 28 & -0.040 & -0.080 & 13.881 & 0.988 \\
\hline
\end{tabular}

\begin{tabular}{|c|c|c|c|}
\hline ADF Test Statistic & -6.032041 & $1 \%$ Critical Value* & -4.1219 \\
\hline & & $5 \%$ Critical Value & -3.4875 \\
\hline & & $10 \%$ Critical Value & -3.1718 \\
\hline
\end{tabular}


Selanjutnya berdasarkan tabel 1 maka dapat disimpulkan bahwa Data NBS terkait sudah stasioner, hal ini karena pada grafik autokorelasi (ACF) dan grafik autokorelasi parsial (PACF) beberapa spike (yang direpresentasikan dengan tanda * kalau dalam tampilan format MS Word) masih berada di dalam garis Barlett (garis putus-putus). Indikasi yang lain adalah nilai probabilitas dari lag $1-28$ yang ternyata jauh di atas $\alpha=0.05$, lain halnya untuk kasus non stasioner yang memiliki nilai probabilitas dari lag 1 - 28 akan kurang dari $\alpha=0.05$. Secara teori ekonometrika adalah logis kalau NBS sudah ada stasioner tanpa differencing. Hal itu karena NBS selisih foreign buy dan foreign sell terhadap saham HMSP. Dalam analisis uji akar unit (ADF) bagian bawah tabel 1, maka data NBS ini juga stasioner [lihat nilai ADF $=-6.032041$ ].

\section{Analisis Pembentukan Model Net Buying Selling (NBS) \\ Model AR (1)}

Melihat hasil akhir model NBS dengan AR (1) maka kita dapat menyaksikan bahwa determinan AR (1) tidak memiliki pengaruh signifikan terhadap $\mathrm{NBS}_{\mathrm{t}}$. Sebagaimana diketahui bahwa AR (1)

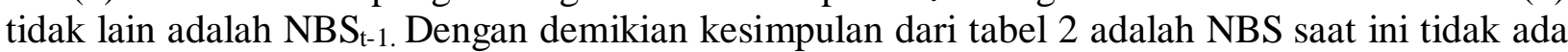
hubungannya dengan NBS kemarin dan sebelumnya untuk kasus pembelian saham HMSP oleh Philip Morris. Temuan ini tidak sejalan dengan Saidah (2006), Tambunan \& Fauzie (2014), namun justru mendukung temuan Nugroho, et.al. (2014) tentang adanya fenomena pembalikan modal (capital flight). Dalam kasus akuisisi HMSP oleh Philip Morris dimungkinkan terjadi mengingat HMSP adalah saham LQ 45 dan sebagian investor HMSP yang asing juga merupakan pihak stakeholder yang memiliki kepentingan atas akuisisi tersebut.

Tabel 2. Analisis Model NBS dengan AR (1)

\begin{tabular}{|l|r|r|r|r|}
\hline \multicolumn{1}{|c|}{ Variable } & Coefficient & Std. Error & t-Statistic & Prob. \\
\hline \multicolumn{1}{|c|}{ C } & -94805.89 & 356892.8 & -0.265642 & 0.7915 \\
\hline \multicolumn{1}{|c|}{ AR(1) } & -0.110247 & 0.130650 & -0.843837 & 0.4023 \\
\hline R-squared & 0.012338 & Mean dependent var & -100327.1 \\
\hline Adjusted R-squared & $\mathbf{- 0 . 0 0 4 9 8 9}$ & S.D. dependent var & 3035593. \\
\hline S.E. of regression & 3043156. & Akaike info criterion & 32.72800 \\
\hline Sum squared resid & $5.28 \mathrm{E}+14$ & Schwarz criterion & 32.79842 \\
\hline Log likelihood & -963.4760 & F-statistic & 0.712061 \\
\hline Durbin-Watson stat & 1.972910 & Prob(F-statistic) & 0.402288 \\
\hline
\end{tabular}

\section{Model MA (1)}

Seperti hasil pengujian dengan model AR (1) ternyata model prediksi atas NBS juga tidak efektif untuk MA (1) yang tidak lain adalah error dari $\mathrm{NBS}_{\mathrm{t}-1}$. Hasil ini kembali memperkuat Saidah (2006), Tambunan \& Fauzie (2014) bahwa NBS saat ini tidak dipengaruhi oleh NBS sebelumnya. Selain itu kembali memperkuat Nugroho, et.al. (2014) tentang adanya capital flight dalam kasus investasi di negara berkembang baik Foreign Direct Investment dan Portfolio Investment. Dalam kasus akuisisi HMSP oleh Phillip Morris maka berlaku keduanya.

Tabel 3. Analisis Model NBS dengan MA (1)

\begin{tabular}{|l|r|r|r|r|}
\hline \multicolumn{1}{|c|}{ Variable } & Coefficient & Std. Error & t-Statistic & Prob. \\
\hline \multicolumn{1}{|c|}{ C } & -58684.50 & 348454.3 & -0.168414 & 0.8668 \\
\hline RA(1) & -0.114129 & 3.487011 & -0.032730 & 0.9740 \\
\hline Adjusted R-squared & 0.012375 & Mean dependent var & -52005.00 \\
\hline S.E. of regression & $\mathbf{- 0 . 0 0 4 6 5 4}$ & S.D. dependent var & 3032943. \\
\hline Sum squared resid & 3039992. & Akaike info criterion & 32.72537 \\
\hline Log likelihood & $5.36 E+14$ & Schwarz criterion & 32.79518 \\
\hline Durbin-Watson stat & -979.7612 & F-statistic & 0.726714 \\
\hline
\end{tabular}




\section{Model ARMA (1,1)}

Saat melakukan analisis dengan model ARMA $(1,1)$ yang tidal lain adalah manifestasi dari teknik peramalan Box \& Jenkis maka diperoleh hasil yang positif yakni $\mathrm{NBS}_{\mathrm{t}}$ dipengaruhi oleh $\mathrm{NBS}_{\mathrm{t}-1}$ melalui representasi variabel AR (1). Hasil ini tidak mendukung Saidah (2006), Tambunan \& Fauzie (2014) dan Nugroho (2014) namun justru mendukung Indawan (2013), Dityadarma (2014), Bryne \& Fiess (2016) dan Vo (2018). Inti hasil studi mereka adalah untuk melakukan analisis prediksi NBS seperti pada tabel 4 maka sangat direkomendasikan model ARMA (1,1). Hanya melihat hasil tabel 4 ini maka determinannya adalah AR (1) bukan MA (1).

Tabel 4. Analisis Model NBS dengan ARMA $(1,1)$

\begin{tabular}{|l|r|r|r|r|}
\hline \multicolumn{1}{|c|}{ Variable } & Coefficient & Std. Error & t-Statistic & Prob. \\
\hline C & -186966.9 & 267474.0 & -0.699009 & 0.4874 \\
\hline AR(1) & 0.526195 & 0.255290 & 2.061161 & 0.0439 \\
\hline MA(1) & -0.685207 & 2.643741 & -0.259181 & 0.7964 \\
\hline R-squared & 0.106511 & \multicolumn{2}{|c|}{ Mean dependent var } & -100327.1 \\
\hline Adjusted R-squared & $\mathbf{0 . 0 7 4 6 0 0}$ & S.D. dependent var & 3035593. \\
\hline S.E. of regression & 2920170. & Akaike info criterion & 32.66169 \\
\hline Sum squared resid & $4.78 \mathrm{E}+14$ & Schwarz criterion & 32.76733 \\
\hline Log likelihood & -960.5199 & F-statistic & 3.337814 \\
\hline Durbin-Watson stat & 2.055678 & Prob(F-statistic) & 0.042707 \\
\hline
\end{tabular}

Setelah memperoleh hasil pada tabel 4 di atas maka di bawah ini kita dapat melakukan spesifikasi model yang tujuanya adalah menjabarkan tabel estmation command, estimation equation dan model akhir persamaan yang dijalankan dengan software EVIEWS. Prosedur spesifikasi ini sudah sesuai dengan Frensidy (2006), Surjawan (2007) dan Hermanto (2009).

Tabel 5. Spesifikasi Model NBS dengan ARMA $(1,1)$

$$
\begin{aligned}
& \text { Estimation Command: } \\
& ================== \\
& \text { LS NET_BUY_SELL01 C AR(1) MA(1) } \\
& \text { Estimation Equation: }
\end{aligned}
$$

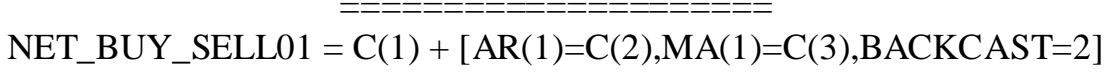

Substituted Coefficients:

$$
\text { NET_BUY_SELL01 }=-186966.87+[\text { AR(1)=0.5261945128,MA }(1)=-0.6852071533, \text { BACKCAST }=2]
$$

\section{Analsis Perbandingan Hasil Prediksi dan Nilai Aktual Net Buying Selling}

Bagian akhir dari analisis ini adalah membuat perbandingan hasil prediksi dan nilai aktual dari NBS. Dan jika dilihat dari grafik 1, maka volatilitas dari NBS ini menunjukkan adanya nilai aktual NBS. Nilai aktual NBS yang naik dan turun memang mengindikasikan adanya dinamika keluar masukya aliran modal asing di Indonesia. Khususnya pada kasus akuisisi HMSP oleh Phillip Morris maka terindikasi bahwa para investor asing memanfaatkan benar situasi sebelum dan setelah akusisi dengan melakukan strategi entry dan exit secara efektif. Begitu mendekati hari $\mathrm{H}$ pengumunan akuisisi oleh pihak otoritas bursa, maka mereka akan melakukan aksi entry yakni melakukan akumulasi pembelian dan begitu setelah proses akusisi ini berlangsung dan jika mereka kecewa maka mereka akan melakukan aksi exit. Nampak pada gambar 1 periode 30 yakni setelah bulan April setelah akusisi 12 Maret 2005 mereka melakukan akumulasi penjualan. Meskipun yang menariknya adalah setelah periode 30 hari itu mereka masuk kembali ke HMSP. 


\section{Gambar 1. Hasil Perbandingan NBS Aktual dan}

NBS Predicted dari ARMA $(1,1)$.

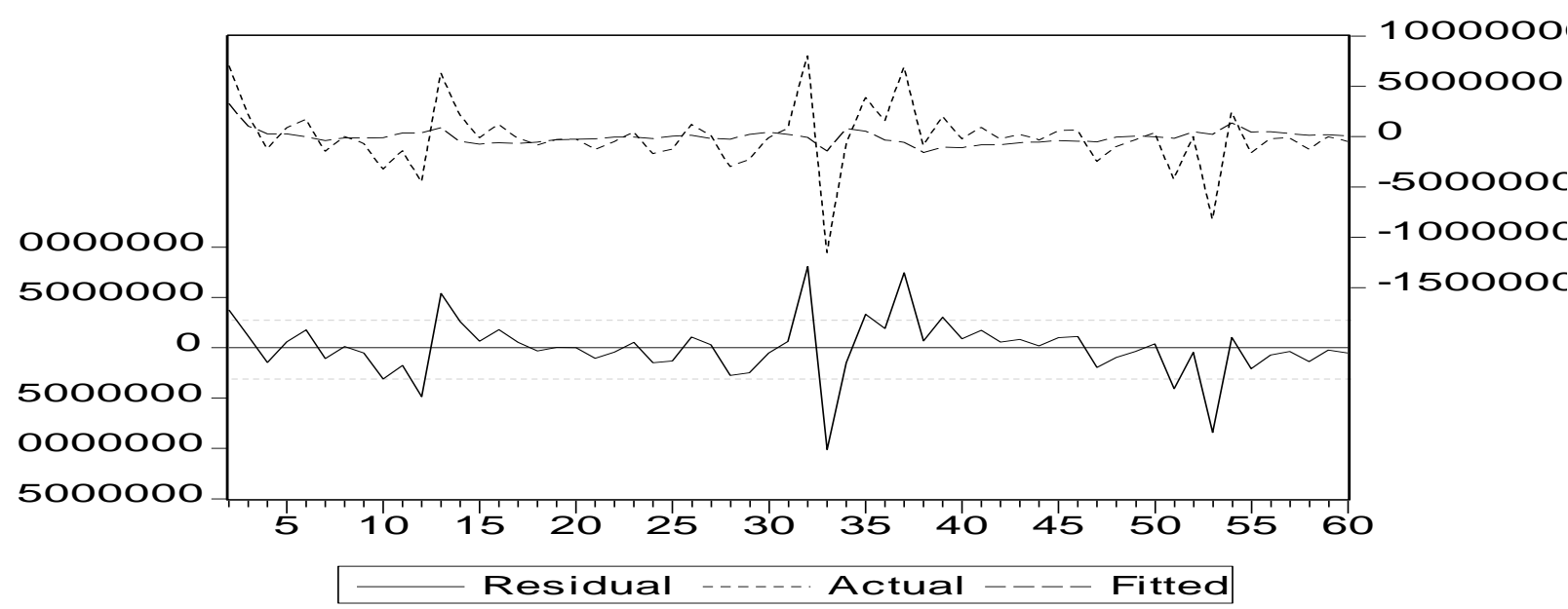

Gambar 1 di atas juga mengambarkan hasil model prediksi dengan ARMA $(1,1)$ untuk NBS yang hasilnya ada di bagian atas yang gambarnya adalah putus-putus berbentuk garisnya hampir datar. Pola yang datar ini menunjukkan adanya titik mean reverting dari gerakan data NBS aktual yang mengindikasikan adanya intervensi dari pihak otoritas bursa bekerjasama dengan otoritas moneter untuk mencegah makin meningkatnya capital flight dalam kasus akuisisi HMSP. Mengingat naiknya capital flight ini berpotensi menurunkan IHSG saat itu oleh karena HMSP adalah salah satu saham LQ 45 terbaik bersama ASII, TLKM, UNVR dan INDF.

Secara teori model ARMA $(1,1)$ dari hasil studi ini dapat dijabarkan sebagai berikut:

$$
\text { NET_BUY_SELL01 } t=\left(1-\rho_{1}\right) \delta+\rho_{1} \text { NET_BUY_SELL01 } t-1+\delta_{t}+\Phi \delta_{t-1}
$$

Secara keseluruhan variabel penentu NBS ini adalah p1 yakni AR (1) merujuk tabel 4. Nilai yang diperoleh untuk $\mathbf{\rho}$ sebesar 0.526195 dengan nilai t-hitung 2.061 (siginifikan pada level 5\%.).

\section{KESIMPULAN DAN SARAN}

Berdasarkan analisis ekonometrika time series mulai dengan uji stasioneritas ternyata terbukti bahwa variabel net buying selling sudah stasioner tanpa differencing prosess. Kedua hasil uji stasioneritas yakni uji korelogram membuktikan dari lag 1 - 28 tanda * atau spike dari net buying selling masih dalam batas garis Barlett untuk grafik ACF dan PACF. Sedangkan berdasarkan uji unit root ADF (random walk with drift and trend) terbukti nilai ADF-statistik sebesar -6.032041 masih lebih kecil dari nilai ADF-kritis $(\alpha=5 \%)$. Kemudian pada waktu melakukan uji identifikasi model mulai dari $\operatorname{AR}(1)$, MA(1), ARMA $(1,1)$ akhirnya penulis mendapat model terbaik yakni ARMA $(1,1)$ dengan dasar signifikannya variabel AR (1) selain nilai F-hitung, Adj-R ${ }^{2}$, AIC, SIC yang lebih baik. Dengan begitu model peramalannya untuk NBS kasus akuisisi HMSP oleh Phillip Morris adalah ARMA $(1,1)$.

Penelitian ini memiliki keterbatasan karena hanya berfokus pada peramalan model data net buying selling HMSP yang dihubungkan dengan akuisisi PT H.M. Sampoerna oleh Philip Morris. Memang dari penelitian ini sudah diperoleh model ARMA $(1,1)$ untuk net buying selling; hanya saja model ini belum cukup menggambarkan apakah ada ekses dari akuisisi Philip Morris ke Sampoerna mengingat karakter investornya bisa jadi berbeda walaupun secara global mereka ini investor langsung dan tidak langsung dapat saling berhubungan melalui broker besar 
Merryl Lynch, Nomura, J.P. Morgan, McKinsey dan lainnya. Untuk mengatasi keterbatasan ini maka dapat dibangun model empirik (kemungkinan multinomial logit) yang lebih kuat yakni dengan menambahkan variabel prosentase kepemilikan saham HMSP setelah akuisisi dengan lebih mendeteksi profil investor baik individu dan institusi yang terbukti melakukan pembelian dan penjualan saham HMSP ini selama periode akuisisi ini berlangsung. Kesulitan akses data profil investor nantinya karena harus login khusus ke KSEI bukan menjadi halangan mengingat begitu besar arti variabel net buying selling individu saham yang akan menjadi penentu net buying seling agregat dan patut diwaspadai perilaku investor asing yang senantiasa oportunis.

\section{REFERENSI}

Bryne, J.P. \& N. Fiess (2016), International Capital Flow to the Emerging Market: National and Global Determinant, Journal of International Money and Finance, Vol. 61, pp. 82-100.

Dityadarma, T. (2014), Determinan yang Mempengaruhi Foreig Equity Trading, Karya Tugas Akhir, Departemen Akuntansi Fakultas Ekonomi dan Bisnis Universitas Gadjah Mada, Diunduh dari http://etd.repository.ugm.ac.id/

Frensidy, B, (2006), Pengaruh Net Foreign Fund Flow dan Perubahan Kurs Terhadap Pergerakan Indeks Harga Saham Gabungan Di Bursa Efek Jakarta, Proposal Riset untuk tugas Seminar on Behavioral Finance, Program Doktor Kekhususan Ilmu Manajemen Keuangan FE-UI, hal. 1-11.

Hermanto, B. (2009), Permodelan Mean Process dan Diagnosanya, Materi Kuliah Financial Econometric, PPIM FE-UI, hal. 1-30.

Indawan, F., S. Fitriani, M.I. Permata \& I. Karlina (2013), Capital Flows in Indonesia: The Behavior, The Role and Its Optimality Uses for Economy, Bulletin of Monetary, Economics and Banking, Vol 15. No.3, January, pp. 24-54.

Nugroho, M.N, Ibrahim, T. Winarno \& M. I. Permata (2014), Dampak Pembalikan Modal dan Threshold Defisit Neraca Berjalan terhadap Nilai Tukar Rupiah, Economy, Bulletin of Monetary, Economics and Banking, Vol. 16. No.3, January, pp. 249-276.

Surjawan, A.G.(2007), Kajian Kointegrasi Nilai Investasi Investor Asing dan Domestik dengan LQ45, O/N JIBOR dan Nilai Tukar Dollar Amerika Serikat Terhadap Rupiah, Ringkasan Disertasi Program Doktor Kekhususan Ilmu Manajemen Keuangan FE-UI, hal. 1 - 77.

Saidah, N. (2006), Capital Inflow: Faktor-Faktor yang Mempengaruhi dan Pengaruhnya Terhadap Perumbuhan Ekonomi Di Indonesia, Karya Tugas Akhir Departemen Ilmu Ekonomi, Fakultas Ekonomi dan Manajemen, IPB, hal. 1-170.

Tambunan, K.F. \& S. Fauzie (2014), Pengaruh Capital Inflow dan Capital Outflow di Indonesia Terhadap Nilai Tukar Rupiah, Ekonomi dan Keuangan, Vol.2. No.5, hal. 296-310.

Vo, X.V. (2018), Determinants of Capital Flows to Emerging Economies: Evidence from Vietnam, Financial Research Letters, Vol. 27, December, pp. 23-27. 